\title{
Effect of Fluoride on the Morphology of Calcium Phosphate Crystals Grown on Acid-Etched Human Enamel
}

\author{
Y. Fan ${ }^{\mathrm{a}, \mathrm{b}} \quad$ Z. Sun ${ }^{\mathrm{a}} \quad$ J. Moradian-Oldak ${ }^{\mathrm{a}}$ \\ ${ }^{a}$ Center for Craniofacial Molecular Biology, University of Southern California, Los Angeles, Calif., and \\ bSchool of Dentistry, Louisiana State University Health Science Center, New Orleans, La., USA
}

\section{Key Words}

Biomineralization · Enamel $\cdot$ Erosion · Fluoridated

hydroxyapatite $\cdot$ Nanostructure

\begin{abstract}
The aim of this study was to examine the effect of fluoride ion concentration on the morphology of calcium phosphate crystals grown on acid-etched enamel as a model for tooth enamel erosion. Samples were immersed in calcification solution for $16 \mathrm{~h}$ and changes in crystal morphology were monitored by field emission scanning electron microscopy. Without fluoride, plate-like octacalcium phosphate crystals (20 $\mathrm{nm}$ thick, 2-10 $\mu \mathrm{m}$ wide) were formed. With 1-10 $\mathrm{mg} / \mathrm{l}$ fluoride, arrays of denser needle-like nanocrystals (20-30 $\mathrm{nm}$ wide, $>500 \mathrm{~nm}$ in length) were formed. We conclude that there is a minimal fluoride concentration $(1 \mathrm{mg} / \mathrm{l})$ that dramatically affects the morphology of calcium phosphate crystals grown on etched enamel in vitro.
\end{abstract}

Copyright $\odot 2009$ S. Karger AG, Basel

The hierarchical structure of dental enamel contains organized nanocrystals of carbonated fluoridated hydroxyapatite, which make the tooth surface highly abrasion-resistant with an interesting combination of wear and fracture resistance [Boyde, 1997]. However, exposure of dental enamel to extreme acidic $\mathrm{pH}$ in the oral cavity, either from extrinsic sources (diet) or intrinsic factors (reflux disorders), leads to dental erosion [Meurman and ten Cate, 1996; Lussi et al., 2004; Honório et al., 2008]. Dental erosion, which is the loss of enamel mineral due to acidic exposure not involving bacteria, has been directly associated with disorders such as bulimia nervosa and chronic gastroesophageal reflux [Nunn, 1996].

In the last five decades, fluoride has been used for the treatment of dental erosion and caries prevention through different modalities [ten Cate, 1997]. In addition, the effect of fluoride on the nanostructure of remineralized apatite has been well documented [Aoba, 1997; Robinson et al., 2004]. However, the optimal dose of fluoride resulting in a positive effect on enamel hydroxyapatite remineralization with minimum risk of toxicity has not been well documented.

A future alternative approach to treat affected enamel would be strategies to reconstruct a synthetic enamel-like structure of hydroxyapatite nano-rods from supersaturated calcium phosphate solution [Yamagishi et al., 2005; Zhan et al., 2005; Chen et al., 2006; Ye and Wang, 2007]. Methods used in the past by various investigators involved extreme conditions such as the application of high temperature, high pressure, or extreme acidic conditions, which are not practical in the clinical setting. The presence of $0.1-2 \mathrm{mg} / \mathrm{l}$ fluoride in the mineralization solution

\section{KARGER}

(C) 2009 S. Karger AG, Basel

Fax +41613061234 E-Mail karger@karger.ch www.karger.com www.karger.com/cre
Janet Moradian-Oldak

Center for Craniofacial Molecular Biology

University of Southern California, 2250 Alcazar Street, CSA103, HSC

Los Angeles, CA 90033 (USA)

Tel. +1 323442 1759, Fax +1 323442 2981, E-Mail joldak@usc.edu 
is known to promote hydrolysis of octacalcium phosphate (OCP) to apatite [Moriwaki et al., 1983; Iijima and Moradian-Oldak, 2005]. It has also been shown that at 0.1-1 ppm F the ribbon-like OCP changes to an interlayered structure, and at $2 \mathrm{mg} / \mathrm{l}$ needle-shaped apatite crystals were produced [Iijima, 2001]. During enamel development, F may facilitate the fast deposition of mineral [Robinson et al., 2004]. However, direct evidence of the effect of $\mathrm{F}$ ion on the morphology and nanostructure of crystal growth at a nanoscale level on an enamel surface has not been reported.

In the present study, we investigated the effect of fluoride ion concentration on the morphology of calcium phosphate crystals grown on an acid-etched enamel surface as a model for tooth enamel erosion. We applied a biomimetic strategy in which supersaturated calcification solutions were used to initiate the growth of calcium phosphate crystals on the etched enamel surfaces [Wang et al., 2004]. Our long-term objective is to develop strategies for application of fluoride in reconstructing tooth enamel [Fan et al., 2009].

\section{Materials and Methods}

\section{Tooth Preparation}

Human third molars without fillings (extracted following the standard procedures at the University of Southern California School of Dentistry and used with Institutional Review Board approval) were selected. The teeth were treated with $3 \%$ sodium hypochlorite and sliced into 0.2 - to $0.5-\mathrm{mm}$-thick samples as previously described [Fan et al., 2009]. Each tooth slice was first etched with a $3 \% \mathrm{HNO}_{3}$ solution for $50 \mathrm{~s}$, rinsed with about $20 \mathrm{ml}$ running deionized water, and then immediately immersed in $12 \mathrm{ml}$ freshly prepared biomimetic calcification solution.

\section{Calcification Solution}

Coatings were obtained by immersing the tooth slices in the calcification solution containing $2.58 \mathrm{mM}$ calcium $\left(\mathrm{CaCl}_{2} \cdot 2 \mathrm{H}_{2} \mathrm{O}\right.$, $>74.4 \% \mathrm{CaCl}_{2}$, Curtin Matheson Scientific, Houston, Tex., USA), $1.55 \mathrm{mM}$ phosphate $\left(\mathrm{KH}_{2} \mathrm{PO}_{4},>99 \%\right.$, EM Science, Gibbstown, N.J., USA) and $180 \mathrm{mM} \mathrm{NaCl}$ at $37^{\circ} \mathrm{C}$, buffered by $50 \mathrm{mM}$ Tris$\mathrm{HCl}$. The $\mathrm{pH}$ of the calcification solution was adjusted with $1 \mathrm{M}$ $\mathrm{HCl}$ to 7.60 using a 718 STAT Titrino (Metrohm, Herisau, Switzerland). The relative supersaturation values $(\sigma)$ were calculated by the SPEC96 speciation program with the Davies extension of the Debye-Hückel equation, using mass balance expressions for total calcium and total phosphate with appropriate equilibrium constants as previously described [Wang et al., 2006]. Fluoride, from $\mathrm{NaF}$ (>99\%, Sigma-Aldrich, St. Louis, Mo., USA), was added to obtain the final desired concentrations of fluoride just before immersing the tooth slice. The mineralization solution containing the tooth slice was sealed in a 20 - $\mathrm{ml}$ scintillation vial and incubated at $37^{\circ} \mathrm{C}$ statically for $2-30 \mathrm{~h}$.

Fluoride and Calcium Phosphate Crystal Morphology
Characterization of the Crystals in Coatings

Tooth slices with the coating were sputtered with carbon to a thickness of $5 \mathrm{~nm}$ for conductivity, and secondary electron images were acquired by a field emission scanning electron microscope (FE-SEM) at $5 \mathrm{kV}$ (Leo, $1550 \mathrm{VP}$ ). Elemental analysis was achieved by means of an Oxford INCA Energy 300 X-ray Energy Dispersive Spectrometer system attached to the SEM. Attenuated total reflection Fourier transformed infrared (ATR-FTIR) was obtained from a diamond accessory (Gladi-Diamond ATR, Pike Technology, Madison, Wisc., USA) attached to a Jasco 2000 FTIR system. Infrared spectra were taken at $4 \mathrm{~cm}^{-1}$ intervals over the $4,000-500 \mathrm{~cm}^{-1}$ range for a total of 30 scans. The mineralized samples for FTIR were prepared freshly and air-dried $3 \mathrm{~h}$ before the test. The coating on the enamel was carefully brought into contact with the diamond crystal surface and compressed by the clamp tip at 30,000 psi. The spectra were converted to transmission mode by the FTIR software.

\section{Results}

The effect of fluoride concentration on the morphology of calcium phosphate crystals formed on acid-etched enamel surfaces was tested after 16-hour deposition, in the presence of $0,0.1,0.5$ and $1 \mathrm{mg} / \mathrm{l}$ fluoride in the supersaturated calcification solution (fig. la-c). Relative supersaturation values $(\sigma)$ were calculated to be 3.08 for OCP, 24.7 for hydroxyapatite and 25.4 for FAP after addition of $52.6 \mathrm{nM} \mathrm{NaF}(1 \mathrm{mg} / \mathrm{l} \mathrm{F})$. The blue shift in the ATR-FTIR spectrum of the $v 4$ band from $561 \mathrm{~cm}^{-1}$ (typical of hydroxyapatite) to $557-555 \mathrm{~cm}^{-1}$ (typical of OCP) indicated that the mineral phase of the coating formed without fluoride was mainly OCP (fig. 1d) [Fowler et al., 1993; Wang et al., 2004]. The morphology of the OCP crystals was flake-like with $5-10 \mathrm{~mm}$ width and $20 \mathrm{~nm}$ thickness (fig. 1a). This morphology was also found in previous biomimetic mineralization studies [Abe et al., 1990; Wen et al., 1998]. The concentration of fluoride affected the morphology of crystals formed on the enamel surface dramatically. At $0.5 \mathrm{mg} / \mathrm{l}$ fluoride, the majority of the crystals had a plate-like morphology (fig. 1b). Careful examination of the OCP (100) crystal plane at higher magnification revealed the presence of short plates, 5-10 $\mathrm{nm}$ in width and length, growing on the large (100) plane (fig. 1b, inset). The coating deposited in the calcification solution with $1 \mathrm{mg} / \mathrm{l}$ fluoride became denser (fig. 1c) and the majority of crystals had a needle-like shape over 500 $\mathrm{nm}$ in length with a $20-30 \mathrm{~nm}$ diameter (fig. 1c, inset). Similar needle-like crystals were found in the coating deposited at $2-10 \mathrm{mg} / \mathrm{l}$ fluoride (data not shown). Observations at other time periods showed that the coatings had begun to form at $2 \mathrm{~h}$ and even at this stage the morphol-

Caries Res 2009;43:132-136 

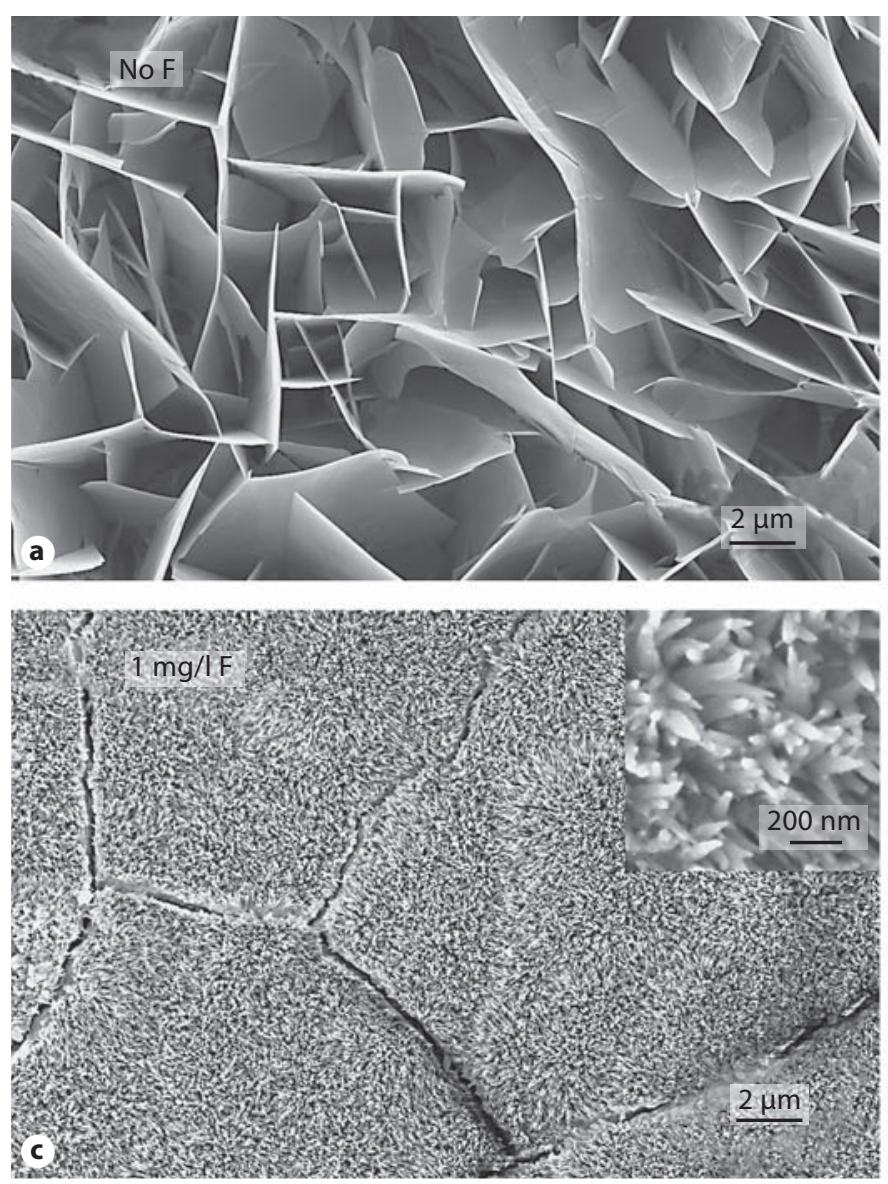

Fig. 1. a-c SEM images of the coating deposited on enamel during $16 \mathrm{~h}$ in the presence of 0 (a), 0.5 (b), or 1 (c) $\mathrm{mg} / \mathrm{l}$ fluoride. Coating topography and crystal morphology progressively change from porous flake-like apatite to needle-like fluoridated hydroxyapatite nanocrystals array with increasing fluoride concentration. Inset in b shows short nano-needles (arrow) formed on the (001)

ogy of the deposited crystals was the same as at $16 \mathrm{~h}$, for all fluoride concentrations. The FTIR spectrum of the mineral phase formed in the presence of $1 \mathrm{mg} / \mathrm{l}$ fluoride was similar to that of apatite (fig. 1d). FTIR spectra also showed the similarity between native enamel and the coating formed in the presence of $1 \mathrm{mg} / \mathrm{l} \mathrm{F}$ (fig. 1d). The absorbance band at $900-1,100 \mathrm{~cm}^{-1}$ was attributed to a $\mathrm{PO}_{4}$ group. A $v 4$ band of $\mathrm{PO}_{4}^{3-}$ at $550-650 \mathrm{~cm}^{-1}$ indicated that the coating was mostly composed of hydroxyapatite. Elemental analysis by Energy Dispersive Spectrometer of the coating containing needle-like crystals prepared with $1 \mathrm{mg} / \mathrm{l} \mathrm{F}$ revealed a Ca/F ratio of 9.8 and a $\mathrm{Ca} / \mathrm{P}$ ratio of 1.45. Since no diffraction band for $\mathrm{CaF}_{2}$ was detected in the XRD spectra (data not shown) we concluded that the crystals were fluoridated hydroxyapatite.
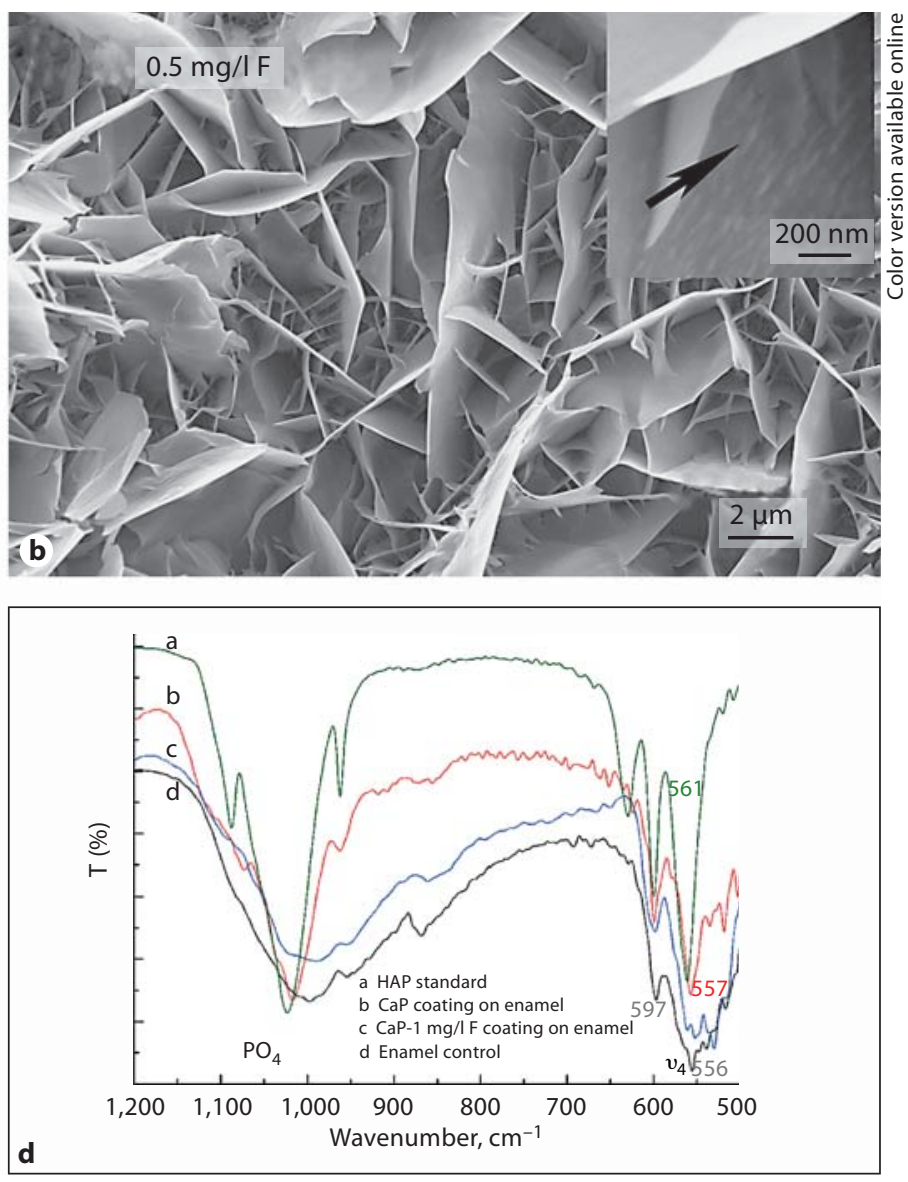

face at high magnification. Inset in c shows the nano-needle array at high magnification. d ATR-FTIR spectra from a hydroxyapatite (HAP) standard, coatings formed in mineralization solution with and without fluoride, and a native enamel surface. The HAP standard has an $\mathrm{OH}^{-}$band at $629.8 \mathrm{~cm}^{-1}$, and $\nu 4$ bands at 599.5 and $560.8 \mathrm{~cm}^{-1}$.

\section{Discussion}

Fluoride ion-containing reagents have been applied routinely in caries prevention and treatment of dental erosion. However, the optimal F concentration to facilitate effective enamel remineralization is unknown. Clinically, fluoride concentration can be as high as $2.26 \%$ $(w / w) ~ F$ to treat etched enamel [Beltrán-Aguilar et al., 2000]. Whether such a high concentration of $\mathrm{F}$ can promote sufficient fluoridated hydroxyapatite formation is, however, not clear.

The treatment of apatite crystals with fluoride solution can cause mineral loss and the replacement of phosphate with fluoride ions [Malaowalla and Myers, 1962]. It is well known that exposure to a fluoride-containing so- 
lution can cause spherical $\mathrm{CaF}_{2}$ precipitates on enamel surfaces. Such $\mathrm{CaF}_{2}$ precipitation was thought to promote fluoride release and remineralization of enamel hydroxyapatite [Francis et al., 1968; Caslavska et al., 1975]. Our results, however, show that under controlled conditions fluoride can be incorporated directly into fluoridated hydroxyapatite grown on an etched enamel surface without the formation of spherical $\mathrm{CaF}_{2}$ particles. Due to increasing concerns over the side effects from exposure to high concentrations of fluoride [Aoba and Fejerskov, 2002; Marthaler, 2004], the application of a low concentration of fluoride would be more appropriate to promote fluoridated hydroxyapatite mineralization for caries prevention or erosion treatment.

Detailed studies on the seeded growth of apatite from supersaturated solution have suggested that OCP may be a precursor of the apatite phase in vitro [Nancollas and Tomazic, 1974]. Fluoride can accelerate epitaxial growth of apatite crystals on the OCP precursor, changing the crystal morphology [Moriwaki et al., 1983; Iijima et al., 1992]. Changes in the morphology of apatite crystals grown from unstable supersaturated solution as the result of fluoride addition have also been reported previously by Eanes and Meyer [1977], who reported that the presence of fluoride eliminated the formation of the intermediate OCP phase. Fluoride was hypothesized to reduce growth of (100) of OCP and to cause needle-like crystal structure formation [Iijima, 2001]. In view of this accumulating knowledge on the effect of fluoride on calcium phosphate mineral phase and morphology, we adopted a biomimetic strategy to develop a technique for enamel remineralization in the presence of fluoride. We found that as little as $1 \mathrm{mg} / \mathrm{l}$ fluoride promoted formation of an array of 20-50 nm diameter needle-like nanocrystals on enamel. Such crystals are similar to native enamel crystals in width and thickness and therefore have the potential to possess similar mechanical properties [Fan et al., 2007]. Although the etched enamel surface used in our study does not model subsurface lesions, the biomimetic calcification system developed could be applied to artificial subsurface lesions used as a model for dental caries [Yamazaki and Margolis, 2008].

In conclusion, fluoride had a dose-dependent effect on crystal morphology in the supersaturated calcification solution used in our in vitro experiments. A uniform coating with organized fluoridated hydroxyapatite crystals was grown in the presence of 1-10 mg/l fluoride. Introducing as little as $1 \mathrm{mg} / \mathrm{l}$ fluoride was effective in altering the crystal nanostructure from porous plate-like OCP to a needle-like array of fluoridated hydroxyapatite nanocrystals. The biomimetic mineralization system used here is a first step towards developing a clinically applicable means of forming an enamel-mimicking mineralized layer, under minimal fluoride exposure, on eroded or damaged tooth enamel [Fan et al., 2009].

\section{Acknowledgements}

Supported by NIH NIDCR Grants DE-13414, DE-15644. We thank Dr. Lijun Wang for assisting us to calculate the degree of supersaturation.

\section{References}

Abe Y, Kokubo T, Yamamuro T: Apatite coating on ceramics, metals and polymers utilizing a biological process. J Mater Sci Mater Med 1990;1:233-238.

Aoba T: The effect of fluoride on apatite structure and growth. Crit Rev Oral Biol Med 1997;8:136-153.

-Aoba T, Fejerskov O: Dental fluorosis: chemistry and biology. Crit Rev Oral Biol Med 2002;13: 155-170.

-Beltrán-Aguilar ED, Goldstein JW, Lockwood SA: Fluorides: a review of their clinical use, cariostatic mechanism, efficacy and safety. J Am Dent Assoc 2000;131:589-596.

Boyde A: Microstructure of enamel; in Chadwick DJ, Cardew G (eds): Dental Enamel. Ciba Found Symp 205, pp 18-31. New York, Wiley \& Sons, 1997.
Caslavska V, Moreno EC, Brudevold F: Determination of the calcium fluoride formed from in vitro exposure of human enamel to fluoride solutions. Arch Oral Biol 1975;20:333339.

Chen H, Tang ZY, Liu J, Sun K, Chang SR, Peters MC, Mansfield JF, Czajka-Jakubowska A, Clarkson BH: Acellular synthesis of a human enamel-like microstructure. Adv Mater 2006;18:1846-1851.

Eanes ED, Meyer JL: The influence of fluoride on apatite formation from unstable supersaturated solutions at pH 7.4. J Dent Res 1977;57: 617-624.

-Fan Y, Sun Z, Moradian-Oldak J: Controlled remineralization of enamel in the presence of amelogenin and fluoride. Biomaterials 2009;30:478-483.
Fan Y, Sun Z, Wang R, Abbott C, MoradianOldak J: Enamel inspired nanocomposite fabrication through amelogenin supramolecular assembly. Biomaterials 2007;28: 3034-3042.

Fowler OB, Markovic M, Brown WE: Octacalcium phosphate 3: infrared and Raman vibrational spectra. Chem Mater 1993;5:14171423.

Francis MD, Gray JA, Griebstein WJ: The formation and influence of surface phases on calcium phosphate solids. Arch Oral Biol 1968; 3:83-120.

-Honório HM, Rios D, Santos CF, Magalhaes AC, Buzalaf MA, Machado MA: Effects of erosive, cariogenic or combined erosive/cariogenic challenges on human enamel: an in situ/ex vivo study. Caries Res 2008;42:454459. 
Iijima M: Formation of octacalcium phosphate in vitro; in Chow LC, Eanes ED (eds): Octacalcium Phosphate. Monogr Oral Sci, vol 18. Basel, Karger, 2001, pp 17-49.

- Iijima M, Moradian-Oldak J: Control of apatite crystal growth in a fluoride containing amelogenin-rich matrix. Biomaterials 2005;26: 1595-1603.

- Iijima M, Tohda H, Suzuki H, Yanagisawa T, Moriwaki Y: Effect of $\mathrm{F}^{-}$on apatite-octacalcium phosphate intergrowth and crystal morphology in a model system of tooth enamel formation. Calcif Tissue Int 1992;50: 357-361.

Lussi A, Jaeggi T, Zero D: The role of diet in the etiology of dental erosion. Caries Res 2004; 38:34-44

Malaowalla A, Myers HM: Interaction of sodium fluoride and synthetic apatite. J Dent Res 1962;41:413-419.

-Marthaler TM: Changes in dental caries 19532003. Caries Res 2004;38:173-181.

-Meurman JH, ten Cate JM: Pathogenesis and modifying factors of dental erosion. Eur J Oral Sci 1996;104:199-206.
Moriwaki Y, Doi Y, Kani T, Aoba T, Takahashi J, Okazaki M: Synthesis of enamel-like apatite at physiological temperature and $\mathrm{pH}$ using ion-selective membranes; in Suga S (ed): Mechanisms of Tooth Enamel Formation. Tokyo, Quintessence Publishing, 1983, pp 239-256.

Nancollas GH, Tomazic B: Growth of calcium phosphate on hydroxyapatite crystals: effect of supersaturation and ionic medium. J Phys Chem 1974;78:2218-2225.

Nunn JH: Prevalence of dental erosion and the implications for oral health. Eur J Oral Sci 1996;104:156-161.

Robinson C, Connell S, Kirkham J, Brookes SJ, Shore RC, Smith AM: The effect of fluoride on the developing tooth. Caries Res 2004;38: 268-276.

ten Cate JM: Review on fluoride, with special emphasis on calcium fluoride mechanisms in caries prevention. Eur J Oral Sci 1997;105: 461-465.

Wang J, Layrolle P, Stigter M, de Groot K: Biomimetic and electrolytic calcium phosphate coatings on titanium alloy: physicochemical characteristics and cell attachment. Biomaterials 2004;25:583-592.
Wang LJ, Tang R, Bonstein T, Bush P, Nancollas $\mathrm{GH}$ : Enamel demineralization in primary and permanent teeth. J Dent Res 2006;85: 359-363.

Wen HB, de Wijn JR, Cui FZ, de Groot K: Preparation of bioactive Ti6Al4V surfaces by a simple method. Biomaterials 1998;19:215221.

Yamagishi K, Onuma K, Suzuki T, Okada F, Tagami J, Otsuki M, Senawangse PA: Synthetic enamel for rapid tooth repair. Nature 2005; 433:819.

Yamazaki H, Margolis HC: Enhanced enamel remineralization under acidic conditions in vitro. J Dent Res 2008;87:569-574.

Ye W, Wang XX: Ribbon-like and rod-like hydroxyapatite crystals deposited on titanium surface with electrochemical method. Mater Lett 2007;61:4062-4065.

Zhan JH, Tseng YH, Chan JC, Mou CY: Biomimetic formation of hydroxyapatite nanorods by a single-crystal-to-single-crystal transformation. Adv Funct Mater 2005;15:20052010 . 